
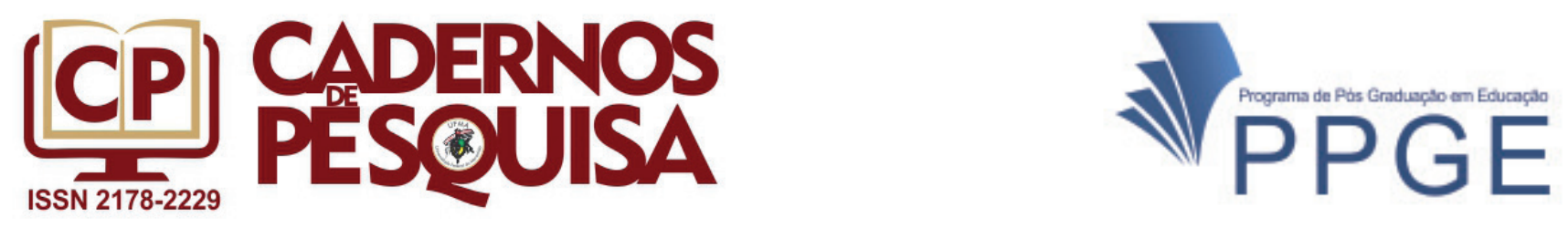

\title{
O conceito de "infância" no contexto da modernidade europeia (séculos XVII-XIX)
}

\author{
The concept of "childhood" in the context of european \\ modernity (XVII-XIX centuries)
}

\section{El concepto de "infancia" en el contexto de la modernidad europea (séculos XVII-XIX)}

\author{
Dulce Regina Baggio Osinsk \\ http://orcid.org/0000-0002-3506-4974 \\ Amanda Siqueira Torres Cunha \\ (iD) http://orcid.org/0000-0002-2984-9708
}

\begin{abstract}
Resumo: Este artigo analisa o conceito de "infância" a partir de formulações que marcaram a modernidade, inserindo-se no campo das pesquisas em história intelectual da educação e relacionando-se de modo mais específico com a história dos conceitos. A investigação tratará do contexto europeu, definindo como recorte temporal o período entre os séculos XVII e XIX. As reflexões de Reinhart Koselleck a partir do campo da história dos conceitos serão cotejadas com as de autores como Ariès, Becchi, Herrero, Levin e Kohan, que discutem a infância em perspectiva histórica. Como fontes, serão analisados os discuros de intelectuais envolvidos com a infância e sua formação, tais como os mestre de Port-Royal, Immanuel Kant, John Locke, Denis Diderot, Jean Jacques Rousseau, Johann Pestalozzi e Friedrich Froebel, os quais evidenciam a construção, manutenção ou ressignificação do conceito de infância no decorrer do tempo, graças a movimentos de circulação e apropriação. Foi possível perceber, no período analisado, que o conceito de infância em circulação no século XVII e início do século XVIII, relacionado a um número maior de aspectos negativos e concebido como um momento da vida imperfeito, pecaminoso e separado da vida adulta, cedeu paulatinamente lugar, até meados do século XIX, à ideia de um período com características próprias e relevante para a concretização do projeto de homem moderno.
\end{abstract}

Palavras-chave: História da educação; história dos conceitos; conceito de infância; infância e modernidade.

Abstract: This article analyzes the concept of "childhood" from formulations that marked modernity, inserting
itself in the field of research in the intellectual history of education and relating more specifically to the history
of concepts. The research will deal with the European context, defining as temporal cut-off the period between
the seventeenth and nineteenth centuries. Reinhart Koselleck's reflections from the field of concept history
will be compared with authors such as Ariès, Becchi, Herrero, Levin and Kohan, who discuss childhood in his-
torical perspective. As sources, the discourses of intellectuals involved with childhood and its formation, such
as the Masters of Port-Royal, Immanuel Kant, John Locke, Johann Pestalozzi, Friedrich Froebel and Jean
Jacques Rousseau, will be analyzed, which put in evidence the construction, maintenance or re-signification
of the concept of childhood in the course of time, thanks to movements of circulation and appropriation. It was 
possible to perceive, in the analyzed period, that the concept of childhood in circulation in the seventeenth and early eighteenth century, related to a greater number of negative aspects and conceived as a moment of imperfect, sinful life separated from adult life, gradually gave place, until de nineteenth century, to the idea of a period with its own characteristics and relevant to the realization of the modern man project.

Keywords: History of education; history of concepts; concept of childhood; childhood and modernity.

Resumen: Este artículo analiza el concepto de "infancia" a partir de formulaciones que marcaron la modernidad, insertándose en el campo de las investigaciones en historia intelectual de la educación y relacionándose de modo más específico con la historia de los conceptos. La investigación tratará del contexto europeo, definiendo como recorte temporal el período entre los siglos XVII y XIX. Las reflexiones de Reinhart Koselleck a partir del campo de la historia de los conceptos serán cotejadas con autores como Ariès, Becchi, Herrero, Levin y Kohan, que discuten la infancia en perspectiva histórica. Como fuentes, se analizarán los discursos de intelectuales involucrados con la infancia y su formación, como los maestros de Port-Royal, Immanuel Kant, John Locke, Johann Pestalozzi, Friedrich Froebel y Jean Jacques Rousseau, que evidencian la construcción, el mantenimiento o la resignificación del concepto de infancia en el transcurso del tiempo, gracias a movimientos de circulación y apropiación. En el período analizado, el concepto de infancia en circulación en el siglo XVII y el inicio del siglo XVIII, que se relacionó con un número mayor de aspectos negativos, siendo concebido como un momento de la vida imperfecto, pecaminoso y separado de la vida adulta, cedió paulatinamente lugar, hasta el siglo XIX, a la idea de un período con características propias y relevantes para la concreción del proyecto de hombre moderno.

Palabras clave: Historia de la educación; historia de los conceptos; concepto de infancia; la infancia y la modernidad.

\section{Introdução}

O presente estudo insere-se no campo das pesquisas em história intelectual da educação, relacionando-se de modo mais específico com a história dos conceitos, vertente que tem servido de instrumental de análise para a compreensão de disputas semânticas que envolvem conceitos centrais também do campo da educação. Nosso foco centra-se na investigação do conceito de "infância" a partir de discursos e formulações que marcaram a modernidade.

Designada por Berman (2007, p. 24-25) como um conjunto de experiências que envolvem "aventura, poder, alegria, crescimento", mas especialmente "autotransformação e transformação das coisas em redor", a ideia de modernidade se relaciona com alguns fenômenos como as grandes descobertas nas ciências físicas, a industrialização da produção, a explosão demográfica, o crescimento urbano, os sistemas de comunicação de massa e o surgimento dos estados nacionais. Iniciando-se em pleno período do renascimento, embora de maneira ainda insipiente e localizada, os processos de modernização foram caracterizados por transformações de ordem política, social e econômica (BOBBIO; MATTEUCCI, PASQUINO, 1998, p. 768), tendo como alguns de seus marcos a Revolução Francesa, o Iluminismo e o que se convencionou denominar de Revolução Industrial.

Para Touraine (1994, p. 218), o projeto de modernidade não se restringe ao triunfo da racionalidade instrumental, guardando em seu bojo, igualmente, "a emergência do sujeito 
como liberdade e como criação", entendido como "antes de tudo a criação de um mundo regido por leis racionais e inteligíveis para o pensamento do homem" (TOURAINE, 1994, p. 218). Sua existência pressupõe "a interação crescente entre o sujeito e a razão, entre a consciência e a ciência" (TOURAINE, 1994, p. 219). O autor ressalta o aparecimento simultâneo da racionalização e da subjetividade, exemplificadas pelo Renascimento e pela Reforma, movimentos contraditórios, mas complementares. A valorização do indivíduo como ator do processo de modernização teve como um de seus desdobramentos a atenção para a criança, que passou pouco a pouco a ser vista como peça-chave para a construção de uma sociedade moderna.

Para perceber os movimentos empreendidos pelas formulações e usos do conceito de infância, privilegiamos o contexto europeu ${ }^{1}$, definindo como recorte temporal um período relativamente longo, mas necessário para o objetivo proposto. Iniciamos no século XVII, momento em que alguns autores identificam a consciência dessa etapa como separada da vida social adulta, chegando até o início do século XIX, quando percebemos novos direcionamentos semânticos para o termo, coadunando com desejos de estruturação de um projeto civilizatório no qual a infância passaria a significar um período preparatório para o que se considerava o estágio final do homem adulto. Tal período abarca ainda o que Berman (2007, p. 25) caracteriza como a primeira fase da modernidade, momento em que as pessoas ainda não tinham plena consciência de seus processos e apenas começavam a experimentá-los, chegando ao início do momento por ele denominado de segunda fase, inaugurada pela grande onda revolucionária que culminou com a Revolução Francesa, contexto em que ganha vida um "grande e moderno público", que partilha o sentimento de viver em uma era que "[...] desencadeia explosivas convulsões em todos os níveis de vida pessoal, social e política" (BERMAN, 2007. p. 26). Entendemos que tal recorte nos permitirá apreender e problematizar uma gama expressiva de movimentos das variações semânticas desse conceito.

É preciso considerar, no entanto, que a própria origem do conceito de infância é controversa, pois as críticas contemporâneas a tal aspecto apontam para um olhar social de separação entre adultos e crianças mesmo na Antiguidade (SARAT, 2004). No entanto, nosso esforço maior recai sobre a identificação das relações entre os significados de um conceito e os contextos em que este termo é disputado, ao lançarmos um olhar sobre as tensões entre a linguagem e a realidade social.

Para isso, traçamos uma aproximação entre a história os conceitos de Reinhart Koselleck (2006 a, 2006 b, 1996) e as reflexões de autores que discutem a infância em perspectiva histórica, como Ariès (1975), Becchi (1982), Herrero (1997), Levin (2002) e Kohan(2005). Como fontes, analisamos discursos de intelectuais envolvidos com o debate sobre a infância e sua formação, tais como os mestres de Port-Royal, além de Immanuel Kant (1999), John Locke (1978), Johann Pestalozzi (1827, 1998), Friedrich Froebel (1991)

1 Destacamos que o contexto europeu hora problematizado diz respeito ao debate ocorrido na região ocidental do continente, especialmente na França, Inglaterra, Itália e Espanha. 
e Jean-Jacques Rousseau $(1952,2004)$. Alertamos, entretanto, que estes são alguns entre tantos outros possíveis, a exemplo daqueles expressos por personalidades menos paradigmáticas do cenário intelectual.

Nosso estudo pretende contemplar os aspectos hermenêuticos dos discursos, destacando-se como potencial tensionador da suposta imutabilidade das estruturas do tempo por meio da linguagem. Inicialmente, é preciso ressaltar que a vertente da história dos conceitos se estendeu em solo germânico no século XX como um "[...] modo particular de história reflexiva da filosofia e do pensamento político e social" (JASMIM e FERES Jr. 2006, p. 22). Surgia como crítica à tradição por parte de historiadores "[...] no que dizia respeito à inscrição contextual das ideias e conceitos e à crítica ao anacronismo e à essencialidade das ideias" (JASMIN e FERES Jr., 2006, p. 22). De modo análogo, no mundo anglo-saxão, animavam tais debates pesquisadores ligados ao contextualismo linguístico ou ao enfoque colingwoodiano, especialmente na universidade de Cambridge, tais como por Quentin Skinner $^{2}$ e John Pocock ${ }^{3}$, além de Peter Laslett e John Dunn (JASMIN, 2005, p. 27).

As críticas à história das ideias, pensadas como constantes e imutáveis, recaíam sobre a constatação de que elas não são contínuas no tempo. Os distanciamentos entre a história da filosofia e a história das ideias dar-se-iam na problematização dos discursos não de modo interno, mas dos pontos de vista também extratextuais, ao considerar os possíveis constrangimentos originados das conjunturas mais amplas, sejam elas políticas, econômicas ou sociais.

Assim, é preciso ponderar que as palavras possuem significados variáveis, consoantes ao período histórico, ao grupo linguístico e aos leitores (COSTA, 2017). Para além das subjetividades do enunciador, buscamos entender como se deu tal constituição conceitual, o que gerou certo consenso de seu significado e sua consequente duração no tempo. Para Koselleck, é necessário ainda destacar os conceitos em relação às continuidades e às descontinuidades de suas "estruturas", enquanto "circunstâncias que não se organizam

\footnotetext{
2 Representante do contextualismo linguístico, Skinner (2005) chama atenção pelo duplo movimento no estudo da história das ideias. Por um lado, propõe uma ação no sentido de abrir mão de pressupostos sobre o autor analisado, ou seja, de erigir conceitos predeterminados e pretensamente localizáveis em seus discursos. Desse modo, correríamos o risco do impulso de vermos apenas o que aspiramos em nosso autor, incorrendo no que Skinner chama de "mitologia das doutrinas". Assim, em busca de uma coerência, perderíamos de vista a riqueza das tensões e disputas dos discursos. Por outro lado, é igualmente plausível considerar o lugar do qual pesquisamos e as marcas exercidas por nossas contingências. Até nesse ponto o contexto histórico e social revela-se como aspecto impulsionador dos nossos interesses, intenções e enunciações, tanto quanto de nosso autor, pois, antes de um objeto de estudo, este é agente social e por isso, encontra-se envolto em relações contextuais mais complexas.
}

3 Distanciando-se de estudos centrados nos modelos filosóficos intemporais, o estudioso do contextualismo linguístico John Pocock propõe um resgate das condições de um determinado agente na prática do discurso. A enunciação é, portanto, um ato linguístico efetivado em suas especificidades, estas, por sua vez, inscritas em certo tempo e espaço. Para Jasmin (2006, p. 15), a partir destes debates se deu "[...] uma total revisão das abordagens mais influentes do estudo da história do pensamento político que [...] incorrem no erro frequente de projetar expectativas do presente sobre o estudo dos autores do passado, produzindo interpretações que não correspondem ao que esses autores de fato pretenderam comunicar através de seus escritos. Skinner chama essas variantes [...] de mitologias da história do pensamento". 
segundo a estrita sucessão de eventos passados. Elas implicam maior duração, maior estabilidade, alterando-se em prazos mais longos" (KOSELLECK, 2006a, p.135).

No presente trabalho, em especial, a pertinência das nossas fontes situa-se na compreensão de que a história dos conceitos lida com o uso de linguagem específica em situações específicas, nas quais os conceitos são elaborados e usados por falantes específicos (KOSELLECK, 1996, p. 62). Desse modo, a despeito da possível abrangência, na definição das fontes, relacionamos documentos ligados ao debate público e a certo domínio linguístico ou campo semântico (JASMIN, 2005), que levam a perceber a construção, manutenção ou ressignificação do conceito de infância no decorrer do tempo, graças a movimentos de circulação e apropriação.

De acordo com a noção de tempo em Koselleck, cada período presente ressignifica o passado, definido pelo teórico como "espaço de experiência". Já os sentidos de um devir, um futuro que se articula no presente, são por ele denominados como "horizontes de expectativas". Tais categorias atemporais, na medida em que são inerentes à existência humana, são interdependentes, pois "não há expectativa sem experiência, não há experiência sem expectativa" (KOSELLECK, 2006a, p. 307).

Defendemos que a história dos conceitos, ainda que vinculada ao estudo do pensamento e dos contextos político e social, pode contribuir para os debates da história da educação, uma vez que conceitos também são objetos de disputa nos mais variados projetos situados na esfera educativa. Por isso, os conceitos, assim como os discursos por meio dos quais estes circulam no meio social e o influenciam, também precisam ser adensados e problematizados do ponto de vista histórico e semântico. Torrano e Castillo (2014, p. 177) sinalizam para as relações profícuas entre história dos conceitos e educação:

\footnotetext{
Em qualquer caso, se considerarmos que as lutas semânticas acabam formando parte também da luta política - e por extensão, da história - a História Conceitual implica uma semântica histórica que naturalmente há de interessar a História dos fenômenos educativos: além de recorrer aos conceitos - "infância", "escola", "alfabetização", "instrução", "escolarização", "formação", "pedagogia", "ciência da educação", etc. - deveríamos aprender a tarefa de analisar os discursos e os imaginários pedagógicos através dos quais se transmitiram e canalizaram os distintos ideários e projetos educativos, de acordo com a teoria dos estratos temporais que marcam as distintas velocidades de mudança histórica que influem nos distintos ritmos históricos (Tradução nossa) 4 .
}

\footnotetext{
4 Do original: "En cualquier caso, si consideramos que la lucha semántica acaba formando parte también de la lucha política - y por extensión, de la historia - la Historia Conceptual implica una semántica histórica que naturalmente ha de interesar a la Historia de los fenómenos educativos: además de recurrir a los conceptos - "infancia," "escuela," "alfabetización," “instrucción," "escolarización," "formación," "pedagogía," "ciencia de la educación," etc. - deberíamos emprender la tarea de analizar los discursos y los imaginarios pedagógicos a través de los cuales se han transmitido y canalizado los distintos idearios y proyectos educativos, de acuerdo con la teoría de los estratos temporales que marcan las distintas velocidades del cambio histórico que influyen en los distintos ritmos históricos" (TORRANO; CASTILLO, 2014, p. 177).
} 
Tal potencialidade do estudo histórico dos conceitos na esfera da educação nos autoriza a tecer tais aproximações, conscientes dos limites e potenciais dessa escolha. No presente trabalho, apresentamos um exercício de análise das transformações de um conceito caro à história da educação.

\section{O despertar do conceito de infância}

A partir das perspectivas histórica e sociológica, vários pensadores têm se debruçado sobre a história da infância. Contudo, propomos problematizar os significados do termo ao longo do tempo, ainda que este não seja sempre enunciado formal ou diretamente nos textos analisados, estando, não obstante, presente como categoria necessária para nominar tal etapa da vida.

Distintos autores concordam que o período entre os séculos XVI e XVII, marcado por acentuadas transformações econômicas e sociais, como a ascensão da burguesia e o desenvolvimento de um ambiente cultural, humanista e racionalista, remete ainda ao momento em que sociedades europeias passaram a conceber a noção de separação entre a criança e o adulto. Trata-se, pois, de um processo histórico no qual sobreveio o interesse na distinção entre o universo do homem e o do futuro homem socialmente adequado, para além de um fenômeno natural.

Para Heywood (2004, p. 22), o termo "infância" trata de uma "abstração que se refere à determinada etapa da vida, diferentemente do grupo de pessoas sugerido pela palavra crianças". É preciso considerar, no entanto, que a própria origem do conceito de infância é controversa. As críticas contemporâneas a tal marco dão conta de perceber um olhar social de separação entre adultos e crianças mesmo na Antiguidade, como ressalta Sarat (2004, p. 2). A autora aponta para um longo percurso percorrido desde Platão, que concebia a infância como um período de irracionalidade e a criança como um animal intratável, ardiloso, hábil e atrevido, passando pela ideia de Santo Agostinho da infância como um mal necessário, até o momento em que ela se torna objeto de atenção e preocupações da sociedade adulta.

De acordo com Kohan (2003), na antiguidade clássica o pensamento platônico dava conta de uma concepção de infância, ainda que não empregado o termo, como período em que o sujeito não compreenderia a filosofia, a política e a educação, e que deveria, diante disso, ser superado, não tendo valor por si mesmo. Lustig et al. (2014, p. 7) acentuam que, nesse contexto,

[...] a infância é concebida como possibilidade e inferioridade. Enquanto "possibilidade" significa ser objeto de intencionalidade política numa visão futura, já que a criança não é vista em si como ela é, mas como possibilidade daquilo que será, "inferioridade" significa a criança ser o outro desprezado. 
No livro II de "Republica", Platão (1950, p. 70) acentua a fragilidade interpretativa do período pueril:

[...] criança não pode discernir o que é alegoria do que não é, e as opiniões que acoIhe nesta idade tornam-se, comumente, indeléveis e inabaláveis. É por isso, sem dúvida, que é preciso fazer o máximo para que as primeiras fábulas que ela ouve sejam as mais belas e as mais apropriadas para ensinar-lhes a virtude (tradução nossa $)^{5}$.

De outro modo, nota-se uma perspectiva de plasticidade da mente infantil, que precisava ser exposta a uma produção específica. Sarat (2004) lembra outros indícios levantados por investigadores como Gélis (1991), Heywood (2004), Riché e Alexandre-Bidon (1994), e D'Haucourt (1994), que interpretam que a atenção com a infância igualmente ocorria na Idade Média. Para a autora, a ideia de infância

[...] esteve presente em períodos anteriores, sendo registrada em indícios de escavações arqueológicas, miniaturas de bonecas, a indicar a presença de crianças e um espaço próprio delas no meio social. Além disso, registram-se fontes documentais, como retratos e pinturas, que revelam a presença da infância e a importância dada a ela pelas pessoas antes do século XVII. (SARAT, 2004, p. 2)

Em momento mais maduro de sua trajetória, Philippe Ariès também relativizou os marcos temporais do nascimento da infância como construção social dos séculos XVI e XVII defendidos anteriormente, problematizando, duas décadas depois, sua obra L'enfant et la vie familiale sous l'ancien régime, publicada pela primeira vez, na França, em 1960. Em 1981, veio a público para ressaltar: "se tivesse que escrever este livro hoje, eu me precaveria melhor contra a tentação da origem absoluta, do ponto zero, mas as grandes linhas continuariam as mesmas. Levaria em conta apenas os dados novos, insistiria mais na Idade Média e em seu outono tão rico" (ARIÈS, 1981, p. 17).

Diante de tais aspectos, o conceito de infância, por seu amplo espectro histórico, torna-se também de definição móvel e problemática. A despeito das tensões ${ }^{6}$ entre as interpretações sobre sua origem, Piedrahita et al. (2011) concluem que tais concepções não foram estáveis no tempo, mas, variantes ao sabor das distintas condições sócio-históricas. Além dos diversos tempos envolvidos, tal vocábulo também se pronuncia pelo número de domínios que disputam a autoridade sobre o tema. As concepções trazem variações

5 Do original : 'L'enfant, en effet, ne peut discerner ce qui est allégorie de ce qui ne l'est pas, et les opinions qu'il reçoit à cet âge deviennent, d'ordinaire, indélébiles e et inébranlables. C'est sans doute à cause de cela qu'il faut faire tout son possible pour que les premières fables qu'il entend soient les plus belles et les plus propres à lui enseigner la vertu" (PLATÃO, 1950, p. 70).

6 De acordo com Piedrahita (2004), De Mause (1991)considera que Ariès deixa no limbo a arte da Antiguidade, além de omitir as abundantes provas de que os artistas medievais sabiam pintar crianças com realismo. Levin (2002, p. 211) destaca que as teses centrais de Ariès e de De Mause são contestadas por Linda Pollock (1990) no que se refere à ideia de que não havia a noção de infância na Antiguidade e que os maus-tratos não eram tão comuns como afirmam os autores. 
marcantes de acordo com diferentes tempos e espaços (STEARNS, 2006) ou mesmo considerando-se os vários tipos de infância, conforme alerta Heywood (2004). Desse modo, diferentes autores (BOYDEN, 1997; FAÇANHA, 2011; FREITAS e KUHLMANN Jr., 2002) coadunam com a ideia de muitas infâncias, referindo-se às relações entre os contextos históricos e as variações de sua concepção nos discursos.

É preciso considerar que etimologicamente a palavra infanti vem do latim in-fari, significando aquele que não pode falar (BECCHI, 1982, p. 62). Sua origem, portanto, destaca-se como fase de incompetência linguística. Em boa parte das línguas neolatinas e no inglês, a palavra infância apresenta-se como metonímia, onde a parte que designa a incompetência linguística determina o todo, como pontua a autora. Entretanto, Becchi (1982, p.64) sublinha que "[...] não se trata de uma metonímia pura e simples, porque é expressa em negativo (infanzia), é metonímia em valor de litotes", referindo-se à figura de linguagem que tem o poder de afirmação por meio da negação de um oposto.

Tal aspecto preponderante da incompetência linguística, que o conceito infância denota em sua procedência, permanece no discurso sobre ela. Segundo Becchi (1982, p. 63),

[...] a infância nasce e existe para outro. Não só em um nível do real, onde ela existe em função de seres diferentes (os adultos que as governam e a quem ela será enfim assinalada), mas também a nível do discurso, uma vez que ela é descrita e denotada através de realidades diferentes dela mesma).

Assim, podemos considerar que o processo de constituição histórica do conceito de infância se deve a movimentos que não se originaram de uma noção de competência retórica das crianças. Pelo contrário, pois seja por

[...] vigilância ou empatia, controle ou acompanhamento, a infância não é dita por si, mas por outros [...] ela é enredada nas malhas de uma palavra que não pronuncia por imaturidade de conhecimentos e de expressão, e por invalidez social, mas sobretudo porque, por definição, enquanto in-fans, ela não pode falar. (BECCHI, 1982, p. 64)

Para Ariès (1981), a origem da ideia moderna de infância, traduzida na noção de separação entre os universos adulto e infantil, está relacionada às relações intrínsecas entre o desenvolvimento do processo de escolarização, que demandaria espaços próprios para as crianças, e a definição das responsabilidades familiares sobre a instrução da prole. O autor remarca que a educação da criança na Idade Média configurava-se pela sua presença junto aos adultos, sendo comum que, a partir dos sete anos, estas passassem a viver com outra família. Com o advento dos tempos modernos, a frequência das crianças na escola [..] "deixou de ser reservada aos clérigos para se tornar o instrumento normal da iniciação social, da passagem do estado da infância ao do adulto". Tal condição levaria a uma "[...] nova necessidade de rigor moral dos educadores, e uma preocupação de isolar a juventude do mundo sujo dos adultos para mantê-la na inocência primitiva, a um desejo 
de treiná-la para melhor resistir às tentações dos adultos. Mas ela correspondeu também a uma preocupação dos pais de vigiar seus filhos mais de perto, de ficar mais perto deles e de não os abandonar mais, mesmo temporariamente, aos cuidados de uma outra família". Para o autor, a "[...] substituição da aprendizagem pela escola exprime também uma aproximação da família e das crianças, do sentimento da família e do sentimento da infância, outrora separados" (ARIÉS, 1981, p. 222).

Além do próprio espaço escolar, Norbert Elias (1994) destaca que a separação entre os espaços adulto e infantil, como no caso dos quartos para as crianças, surge mais ou menos a partir dos séculos XVI e XVII, nas casas dos mais abastados, o que se generalizaria para as camadas mais pobres apenas no curso do século XX. Para o autor, esse aspecto foi alimentado por concepções circulantes desde o século $\mathrm{XV}$, segundo as quais as crianças necessitavam de comando e hierarquia ante um convívio social que, até então, não estabelecia diferença entre faixas etárias. Os anos quatrocentos italianos, para Frabboni (1998), podem ser denominados, ainda, como um período da "criança-adulto" ou da "infância negada".

Nesse sentido, Herrero (1997, p. 230, tradução nossa) pontua que "na Inglaterra, desde 1460, podia-se escutar com frequência que 'um homem não deve confiar em uma espada rota, nem em um tolo, nem em uma criança, nem em um fantasma e nem em um bêbado'"' . Desse modo, a autora destaca a visão, em circulação, de valor negativo da competência retórica e da validade social da criança. De outro lado, as percepções de educadores como o italiano Vitorino da Feltre (1378-1446), da Escola Giocosa, no século XV, ou o ensaísta francês Michel de Montaigne ${ }^{8}$ (1533-1592) no século XVI, destacam-se como referências no que tange às especificidades da infância, a exemplo da recusa aos castigos corporais ${ }^{9}$.

Linda Pollock (1990), a partir de ego-documentos originários da Inglaterra e dos EUA do século $X V$, relativiza a severidade com a qual os corpos infantis eram tratados nesse contexto e destaca que a repressão e o demérito do ser criança não foram absolutos. De modo mais próximo ao debate de Pollock (1990), Herrero também ressalta que um segundo significado lhes era atribuído em solo inglês naquele contexto, embora de forma menos frequente, mas com uma potente ressonância cultural. Tratava-se da noção da infância inocente e digna do Reino dos Céus mediante o rito batismal pela Igreja (HERRERO, 1997). Nesse sentido, Ariès enfatiza que o tema da infância sagrada, presente na iconografia

7 Do original: "En Inglaterra, hacia 1460, podía escucharse con asiduidad que 'un hombre no debe confiar en una espada rota, ni en un necio, ni en un niño, ni en un fantasma, ni en un burracho'".

$8 \mathrm{Na}$ obra "Ensaios", especialmente nos capítulos "Pedantismo" e "Da educação das crianças", Montaigne (2016) dirige críticas ao modelo educativo de viés humanista, compreendido como autoritário e pedante.

9 Destacava o filósofo: "Sou inteiramente contrário a qualquer violência na educação de uma alma jovem que se deseje instruir no culto da honra e da liberdade. O rigor e a opressão têm algo de servil e acho que o que não se pode obter pela razão, a prudência, ou a habilidade, não se obtém jamais pela força" (MONTAIGNE, 2004, p. 181). 
francesa a partir do século XIV, ampliava-se ao relacionar-se ao menino Jesus e à virgem criança. Tal imaginário se desdobraria na iconografia leiga dos séculos $X V$ e XVI, momento em que as crianças ganhavam paulatino destaque na família burguesa (ARIĖS, 1981, p. 42-43). Podemos citar como um indício dessa progressiva valorização a mudança ocorrida em relação aos retratos de crianças reais, antes presentes apenas em efígies funerárias, passam também a representar crianças vivas, tornando-se parte dos ambientes familiares (CHARLOT, 1979, p. 100).

Vale ressaltar que tais sentidos constituintes do conceito de infância, em parte coincidentes nas análises mencionadas, também provém dos tipos de fontes analisadas pelos autores, tais como diários pessoais, no caso de Pollock, e iconografias, no caso de Ariès, pois esses gêneros de documentos representam, nos referidos contextos, pequenas parcelas das sociedades que tinham acesso à escrita ou a encomendas de pinturas de gênero.

De todo modo, conforme observa Kramer (2003, p. 87), a ideia de infância, no contexto da modernidade, surgiria com o advento da redução dos índices de mortalidade, fenômeno histórico e social inerente às classes médias burguesas. Assim, as transformações econômicas, políticas e sociais ocorridas na Europa levavam à expressão de dedicação à infância como etapa em separado da vida adulta, o que se dava pari passu com o início do processo de escolarização da criança. $O$ conceito de infância associava-se, portanto, à noção de um porvir, de um futuro social a ser estabelecido: "A ideia de infância não existiu sempre da mesma maneira. Ao contrário, a noção de infância surgiu com a sociedade capitalista, urbano-industrial, na medida em que mudavam a inserção e o papel social da criança na comunidade". (KRAMER, 2006, p. 14)

Levin (2002) destaca que a especificidade da educação das crianças fora marcada, no contexto europeu do século XVII, também por métodos severos. Porém, para Ariès, isto não se limitava à infância, mas relacionava-se aos princípios de hierarquia e autoridade que acompanhavam as demais esferas sociais, sendo o estabelecimento do absolutismo monárquico na Europa parte desse movimento. Para o autor, as atenções da família e da igreja se voltavam à criança, limitando, contudo, a liberdade que esta desfrutava junto aos adultos (ARIĖS, 2002, p. 210). Ele assevera também que "nos séculos XVI e XVII, os contemporâneos situavam os escolares no mesmo mundo picaresco dos soldados, criados, e, de um modo geral, dos mendigos. As pessoas honestas que possuíam algum bem desconfiavam tanto de uns como de outros" (ARIĖS, 1981, p. 172). Corroborando com a perspectiva geral de Ariès, para Clarke (2004), pensar em infância significa considerar um fenômeno moderno ou "um artefato da modernidade".

Como pontua Becchi, na França do século XVII, a infância passava a adquirir um estatuto próprio. Contudo, a autora ressalva que isto se dava meio a uma luta contra 
A autora se refere a um período considerado revelador de rupturas no pensamento educativo-filosófico sobre o conceito de infância. Em especial, destaca a experiência das escolas de Port-Royalou Petites Écoles (1637-1655), destinadas à educação dos filhos dos dirigentes da burguesia francesa. Embora por curto espaço de tempo, tal investimento, bem como os discursos de seus mestres, foi associado a um modelo de educação da criança baseado na intervenção do professor para transformar a infância em etapa propedêutica para a constituição do "bom adulto". Os discursos desses agentes apresentam-se baseados em metáforas sobre a natureza humana e as trevas, na defesa de que "[...] educar significa estar constantemente alerta contra o inimigo por antonomásia que é o mal personificado no demônio" (BECCHI, 1973, p. 68).

Becchi chama a atenção para o arsenal de metáforas empregadas na descrição do enfant nos escritos dos mestres de Port-Royal, tais como "morada de Jesus Cristo", "depósitos preciosos de seus mestres", que também revelam a riqueza das acepções da infância como terreno do possível e "[...] da redenção da graça, e por isso, ocasião eleita do compromisso religioso e social do adulto, que na redenção do fraco e na guerra contra as forças do mal, pratica sua fé" (BECCHI, 1973, p. 68). Para ela, tal tomada do conceito de infância também coincidia com uma metaforização do educador e da obra educativa. Retornando à tradição clássica, o mestre é assimilado como figura de transformação, a exemplo do jardineiro, do oleiro ou do médico, e sua obra é vista como "[...] uma guerra, como luta de um soldado em um país hostil" (BECCHI, 1973, p. 68). Designações de figuras concretas, como o vaso nas mãos do oleiro, apareciam nos escritos dos educadores de Port-Royal, fortalecendo a ideia da criança como categoria em condição humilde e em situação desfavorável, que precisava ser remida pelo adulto. Logo, a voz do infante pouco contribuiria para se atingir o objetivo de salvação de sua pobre alma, cabendo tal peleja ao professor.

O papel educativo, portanto, era estabelecido por metáforas. Sua intervenção, enfim, tinha como princípio prevenir e corrigir a inclinação da criança para o mal e, precisamente por isso, seria necessário ajudá-la e guiá-la em crescimento e formação para a vida prática. Assim, as luzes da razão triunfariam nas débeis mentes infantis. Para isso contribuiriam os programas educacionais, incutindo nela "a aprendizagem racional e a capacidade de resistir às pressões do hábito e do desejo, para submeter-se somente ao governo da razão" (TOURAINE, 1994, p. 218). Os textos dos mestres das Petites Ecoles, enfim, configuram um lugar inaugural para a infância:

Inscrita numa antropologia heterodoxa com relação àquela da Igreja e do Estado, enquadrada numa teoria do ser e sobretudo do agir do homem ao qual se subtrai boa parte das garantias sociais e ideológicas, iluminada por uma gnoseologia racionalista inspirada em Descartes, a qual vê nas ideias claras e distintas e no jugement o eixo da vida epistêmica, a idade não-adulta se torna fulcro de uma operação individual e coletiva inteiramente nova. (BECCHI, 1989, p. 67) 
Como Narodowski (1994) destaca, a partir do século XVII, a Europa passou a ser marcada pela centralidade da escola no discurso pedagógico. Naquele momento, nos mais variados contextos, de Comenius a Salle, sobressaía a ideia da disciplina e da vigilância sobre o corpo infantil. Portanto, "Ao mesmo tempo em que abandona a produção e o núcleo primário social básico, a infância é recolhida pela pedagogia para submeter-se ao regime epistemológico de sua observação e análises e ao regime institucional moderno, que garantirá seu confinamento". (NARODOWSKI, 1994, p. 3)

Enfim, para esses autores, como também para Sarmento e Pinto (1997), no século XVII assistia-se à alvorada do interesse na infância, enquanto construto social, nesse caso, ligado ao ideal civilizador do homem europeu, a ser forjado pela escolarização. De acordo com Becchi (1973, p. 74), "[...] os artifícios retóricos de Port-Royal nos fazem refletir ainda sobre a dificuldade de um acesso não só poético ao mundo infantil, sobre os riscos e impedimentos de um itinerário da palavra na realidade infantil".

Contudo, no cerne do pensamento burguês, o interesse na formação do futuro homem moderno, útil e produtivo, balizado pela racionalidade, abria espaço também para a revisão no trato da criança, semente da transformação social. A exemplo disso, John Locke (1632-1704), no escrito intitulado Some Thoughts Concerning Education, de 1693, destacava, referindo-se ao caso inglês:

Os golpes e os demais castigos servis e corporais não convém, pois, como meio de disciplina na educação de uma criança que queremos fazer um homem prudente, bom e ingênuo e, por conseguinte, raras vezes será aplicado e somente em grandes ocasiões, em casos extremos. (LOCKE, 1986, p.79)

Assim, Locke esboça noções sobre as crianças como indivíduos racionais e merecedores de certos cuidados, prenunciando uma orientação que se acentuaria no século seguinte. De todo modo, permanece a noção de incompetência linguística da infância.

O conceito de infância sofreria relevantes câmbios em sua acepção no século XVIII, cabendo-nos "[...] perguntar que camadas de significado persistem, são traduzíveis e podem ser aplicadas de novo; que linhas de significado são descartáveis; e que camadas novas são acrescentadas" (KOSELLECK, 2006b, p. 107). Como Koselleck (2006a) problematiza, esse período foi marcado por densas transformações na linguagem e visível ressignificação de antigos conceitos, adaptados aos "novos tempos", bem como pela invenção de neologismos, "[...] criados para nomear as novidades da experiência contemporânea" (KOSELLECK, 2006a, p. 10). Afinal, foi um tempo que se caracterizou por profundas transformações políticas e sociais, ocorridas também com relação à imagem do Estado e à burguesia, em meio ao debate intelectual iluminista ${ }^{10}$, que se desdobraria em movimentos como o jacobino na França, na segunda metade do século, além da Revolução Industrial na Inglaterra.

10 Como pontua Fortes (1993), o iluminismo não se trata de um movimento homogêneo, mas destaca em comum , a circulação de um "espírito" baseado na ideia de liberdade. De acordo com Cassirer (1992), tal período fora resultado da sistematização do pensamento filosófico precedente. De outro lado, considera que a partir de uma ruptura com o "espírito de sistema", diga-se metafísico, como freio para a razão filosófica, não 
Nessa conjuntura, desenhava-se uma centralidade dos debates sobre a educação, enquanto tema de domínio filosófico e político, de interesse e demanda pública (SOUZA FILHO, 2015). Tendo-se a Revolução Francesa (1789), no final do século, como emblema de rupturas na função do Estado, a criança tendia a ser considerada matéria de responsabilidade pública e os governos passariam a ocupar-se de seu bem-estar e de sua educação (LEVIN, 2002, p. 229).

O conceito de infância estaria intimamente ligado à educação da criança e à formação do homem moderno. Diante disso, emergia o ensino público no fim do século XVIII, que se dava concomitantemente com o processo de laicização da educação, bem como, de difusão do livro, embora isso não ocorresse de modo homogêneo nas sociedades europeias, como salienta Chartier (2004), ao discutir o problema no âmbito da França:

As evoluções demográficas, que transformaram a estrutura da população de certas cidades, as conjunturas econômicas locais, os fluxos da alfabetização, podem explicar essas variações que atestam globalmente que o século XVIII não é absolutamente marcado por uma difusão contínua da cultura impressa, mas por avanços e recuos, por conquistas seguidas de paralisações, uma vez atingido um primeiro limite social da presença do livro. (CHARTIER, 2004, p. 177)

Contudo, uma vez que os sistemas educacionais estatais também sofriam oposição às suas estruturas, impunham-se disputas sobre o controle da infância e dos modos pelos quais ela seria formada na modernidade. Como ressalta Piozzi (2007, p. 720),

[...] ao longo da Revolução Francesa, o debate em torno da educação pública adquire a dimensão do confronto entre projetos elaborados para a implantação imediata de políticas públicas, travado na Assembleia Legislativa, marcado pela paixão e espírito polêmico tão característicos desses raros e curtos períodos em que as grandes transformações, rápidas e profundas ao mesmo tempo, favorecem a multiplicação e polarização das ideias".

As mudanças no regime demográfico europeu repercutiriam diretamente não só sobre a imagem da criança, mas também sobre as estruturas familiares e a concepção de casamento. Assim, no século XVIII, o vigoroso declínio da mortalidade se somava a uma sólida ascensão econômica da burguesia, aspectos estes que contribuiriam para modificar as ideias circulantes, além de anunciar certo futuro (SNYDERS, 1965, p. 401).

Para Ariès (1981), esse movimento se dava, ainda, por meio das mudanças nas relações sociais das famílias modernas, assinaladas como lugares privados de proteção de sua infância. A substituição da família numerosa do período medieval pelo modelo nuclear, o número menor de filhos e a diminuição da diferença de idade entre os cônjuges foram alguns

se perdia vista, porém, o "espírito sistemático", que "em vez se fechar nos limites de um edifício doutrinal, em vez de restringir-se à tarefa de deduzir verdades da cadeia de axiomas fixados de uma vez por todas, a filosofia deve tomar livremente o seu impulso e assumir em seu movimento imanente a forma fundamental da realidade [...] (CASSIRER, 1992, p. 9). 
dos fatores que contribuíram para que os pais passassem a dedicar mais tempo aos seus filhos, modificando suas relações com o fenômeno da infância (SZABOLCS, 2105, p. 127).

$A$ isso, acrescia-se o engajamento de intelectuais ${ }^{11}$ ligados ao iluminismo na esfera pública, que debatiam os domínios econômico, jurídico e educacional, a exemplo de Kant (1724-1804), Pestalozzi (1746-1827), Froebel (1782-1852), Voltaire (1694-1778), Montesquieu (1689-1755), Diderot (1713-1784) e Rousseau (1712-1778). Para Kelly (2004), sobressaía em tal período um interesse sobre o estudo racional do desenvolvimento do homem e de suas instituições. Não de modo unívoco, contudo, tal conjuntura é assinalada por transformações sobre o lugar social da criança.

É sintomática, nesse sentido, a representação que emerge da carta enviada por Diderot (1821, p. 240) na década de 1770 à Condessa de Forbach, intitulada por ele "Sobre a educação das crianças”. Nela, a infância é vista como um período plástico, a ser moldado pela ação dos pais com o objetivo de formar um futuro homem bom e honesto, sendo para isso necessário incentivar as virtudes da justiça e da firmeza, consideradas por ele mais importantes que qualquer conhecimento adquirido. Seu espírito deveria ser esclarecido e seu gosto cultivado, sendo-Ihe despertado o sentimento da verdade, do belo, do sublime e da decência, o que se faria por meio da imitação ou do emprego de produções da natureza. O exemplo dos pais deveria se dar pelas ações cotidianas, sendo o afeto, a confiança e a amizade as estratégias desejáveis para fazer brotar os sentimentos de dignidade, franqueza e liberdade.

Daquele contexto também são exemplares as produções do filósofo de Genebra Jean Jacques Rousseau, tomadas como tratados pedagógicos, especialmente no caso dos romances Julie ou La nouvelle Héloïse (Julia ou A nova Heloisa), de 1761, e da obra em cinco livros ${ }^{12}$ intitulada L'Émile ou De l'éducation (O Emílio ou Da Educação), de 1762.

11 Vieira (2008) destaca as ambiguidades que historicamente cercam os termos intelligentsia e intelectual. No século XIX, a oposição dos críticos ao envolvimento do intelectual na esfera pública dividiu a França no caso Dreyfus e marcou a jovem elite russa que se levantava contra o czarismo. Como ainda ressalta o autor, se para os opositores, esses intelectuais não deveriam se envolver nas paixões das multidões, no século seguinte tal posicionamento também foi exemplificado por Julien Benda em "A traição dos clérigos", de 1927. Contudo, o século XX ainda assistiu à dignificação do intelectual pelo mesmo motivo que o condenava, ou seja, pelo engajamento na vida política. Tal positividade experimentada pelo intelectual ocorreu como parte, inclusive, do fortalecimento de autorrepresentações graças ao privilegiado lugar de enunciação do intelectual moderno. $\mathrm{O}$ acento sociológico e histórico que teóricos como Mannheim, Bourdieu e Gramsci lançaram sobre atuação do intelectual na cena pública, contribuiu para a "dessacralização" deste, como também ressalta Vieira (2008). Longe de qualquer idealização do intelectual, entendido como aquele cujo produto final do trabalho são as ideias, Sowell (2011) ressalta o que entende como efeitos perigosos dos intelectuais na história. Para ele, o intelectual, por seu papel público, direta ou indiretamente afeta as sociedades, pelo poder de criar e divulgar um conjunto geral de pressuposições e crenças. O autor alerta ainda para o que chama de imunidade de alguns "falsos profetas", referindo-se a condutas irresponsáveis no ato da enunciação (p. 28). Sowell (2011) afirma que as demandas por intelectuais públicos são criadas por eles mesmos. Desse modo, se por um lado, para os pesquisadores os intelectuais não são personagens heroicizados, por outro, o poder de seu discurso permanece bastante evidente nas sociedades contemporâneas.

12 Seguindo a ordem daquilo que o autor destaca no prefácio como "a marcha da natureza", a obra é organizada em consonância com as etapas etárias de Emílio. Primeiro livro: A idade da natureza (infans - 0-2 anos); Segundo livro: A idade da natureza: de 2 a 12 anos): puer; Terceiro livro: a idade da força (12 a 15 
Certos aspectos de seus escritos legariam apropriações da noção da essência da natureza infantil, inclusive, nos discursos de artistas românticos do século seguinte.

Em Emílio, obra que congrega em narrativa ficcional, ao idealizar um menino e a relação com seu preceptor, além de costurar linhas de sua própria experiência como educador, o conceito de infância é marcado como espaço particular do desenvolvimento do homem, raiz de um cuidado para se atingir uma vida feliz, estabelecido por etapas etárias que tornam suas experiências ainda mais específicas. A participação do adulto no processo educativo se faz em relação a cada estação, da infância à fase adulta de Emílio, quando se dá o casamento do jovem. Para Rousseau, portanto, no que diz respeito à infância:

\begin{abstract}
A natureza - quer que as crianças sejam crianças antes de serem homens. Se quisermos perturbar essa ordem, produziremos frutos prematuros que não terão nem madureza nem sabor, e não tardarão a se corromper; teremos doutores infantis e crianças velhas. A infância tem maneiras de ver, de pensar, de sentir que the são próprias. (ROUSSEAU, 2004, p. 76)
\end{abstract}

A especificidade infantil é perceptível, inclusive, no processo de comunicação da criança, pois o próprio choro permitiria a expressão do pequeno até que este aprendesse a se comunicar pela fala. A discurso de Rousseau a definiç a definiço momento necessEm Rousseau, é possível identificar, enfim, a tentativa de se dissolver os litotes no conceito de infância, empregando novas camadas de significados no uso desse termo. Pois, a infância, para além se sua significação como momento necessário e digno de cuidados, passaria a comportar também o sentido de espaço particular de enunciação, em uma tentativa de desfigurar as metáforas que negativizavam os sentidos do conceito.

Seguindo o caminho aberto por Rousseau, o período entre os séculos XVIII e XIX, definido por Hobsawm (1991) como "A era das Revoluções", destacou-se pelo debate que subsidiaria certo ideal de transformação humana para o progresso, pensada, inclusive, por meio da educação das crianças pequenas. As reflexões que se seguiam, como por meio do trabalho de viés filosofo-teológico do educador alemão de matriz protestante Friedrich Froebel (1782-1852), estabeleciam-se ligados a uma tradição do pensamento rousseaniano, embora fossem traçadas especificidades sobre as relações entre infância e educação no desenvolvimento dos projetos políticos que se seguiriam com bases no iluminismo.

Tomando como fonte a obra de Froebel "A educação do homem”, de 1826, é patente a concepção de infância também definida como um momento privilegiado para o desenvolvimento humano por meio da interação com a natureza. Isso se daria através da liberdade para se atingir a harmonia social e divina. Criticando os métodos educativos por demais intervencionistas, que tratavam a criança como "um pedaço de cera, uma massa de argila com a qual se pode modelas o que se quer" (FROEBEL, 2001, p. 26), o autor defendia a

anos); Quarto livro: A Idade da razão e das paixões (15 a 20 anos); Quinto livro: a idade da sabedoria e do casamento (20 a 25 anos). 
infância como um período de desenvolvimento com mais liberdade, considerando que uma educação com excesso de coação e diretividade tenderia a anular, oprimir e perturbar sua espontaneidade. Conforme o educador:

[...] na alma de cada criança - na experiência de cada criança, no ritual de sua evolução, na história do desenvolvimento de cada consciência humana, desde que aparece sobre a Terra - se repete e se reproduz a história da criação de todas as coisas, tal como nos contam os livros dos santos, até o momento em que o homem se reconhece a si mesmo no meio do paraíso terreno, na formosa natureza estendida entendida também ante os olhos da criança. Mais tarde, reproduz-se também, essencialmente em cada criança, o momento que foi o princípio da liberdade da razão em toda espécie humana, criado precisamente para a liberdade. (FROEBEL, 2001, p. 43)

Assim, a exemplo de Rousseau, o conceito de infância em Froebel caracterizava-se como etapa privilegiada da formação do homem moderno e livre, balizado pela razão e pela busca da verdade divina. A fase infantil, oportunizada pela família, designava período de reflexão, experiência e, sobretudo, de atividade.

O trabalho de Froebel, com os seus jardins de infância e a formação de educadoras (jardineiras), sofria resistências no conflituoso contexto da Revolução de 1848, na Alemanha, ao considerarem-se suas ideias perigosas para o Estado (BASTOS, 1991, p. 16). Sua perspectiva sobre a infância travava debate, ainda, com a obra de Pestalozzi, em decorrência de seu contato com o educador suíço. Conforme Amorim (2018, p.14), os movimentos decorrentes da Revolução Francesa e da Restauração, em especial, em sintonia com os debates advindos do iluminismo e do romantismo, apresentam-se como "quadro interpretativo amplo da expressão teórica de Pestalozzi”.

Questões como o "esclarecimento" e o processo de escolarização das camadas populares, movidos pelo fortalecimento de novos modelos de instituições educativas na modernidade, destacam-se como amplos movimentos históricos

[...] nos quais Pestalozzi se insere com uma proposta singular, herdeira da tradição de Rousseau da busca de uma 'educação natural', que veio a catalizar, por sua vez, o processo histórico de consolidação da escola moderna. (AMORIM, 2018, p. 14)

Como Troher (2014) sinaliza, o impacto das obras seminais de Rousseau de 1762, especialmente "O contrato social" e Emílio", confluía para a compreensão da educação pela natureza. Além disso, o papel da mulher na formação da infância também descendia dos debates empreendidos pelo filósofo (ARCE, 2002).

Em "Cartas sobre educação infantil", epístolas escritas entre 1818 e 1819 e destinadas ao educador James Pierpoint Greaves, Pestalozzi (1988, p. 12) ressalta o valor do amor familiar para construção de uma infância ajustada, concebendo em especial a figura materna como fomentadora desse processo: 
Permitam-me repetir que não podermos esperar qualquer melhoria real na educação, que se estenda em uma esfera ampla e continue progressivamente ao longo do tempo, aumentando seu vigor, como deveria, se não começarmos educando as mães. É seu dever, no círculo doméstico, fazer o que a instrução escolar não pode alcançar; prestar a cada criança aquele grau de atenção que uma escola precisa consagrar ao todo; deixar seu coração falar nos casos em que o coração é o meIhor juiz; reunir para o afeto o que a autoridade não teria alcançado. (PESTALOZZI, 1988 , p. 12, tradução nossa) ${ }^{13}$

O trabalho de Rousseau teria, afinal, inaugurado uma era de ressignificação do conceito de infância, positivando-se os usos do termo, ou tratava-se de um resgate de antigas camadas sobrepostas pelo pensamento clássico em Platão sobre infância? Essa última hipótese procede se considerarmos o pensamento de contemporâneos de Rousseau, a exemplo de Kant (1999), que em "Sobre a Pedagogia", redigido na segunda metade do século XVIII como um conjunto de preleções destinadas a seus alunos na universidade de Königsberg, parece resgatar elementos caros ao pensamento platônico, como a noção de plasticidade da mente infantil, mas também a necessidade de educação na infância. Para o filósofo, a natureza não se configuraria como elemento suficiente da condução do homem racional:

\begin{abstract}
Os selvagens jamais se habituam a viver como os europeus, ainda que permaneçam por muito tempo ao seu serviço. O que neles não deriva, como opinam Rousseau e outros, de uma nobre tendência à liberdade, mas de uma certa rudeza, uma vez que o animal ainda não desenvolveu a humanidade em si numa certa medida. Assim, é preciso acostumá-lo logo a submeter-se aos preceitos da razão. Quando se deixou o homem seguir plenamente a sua vontade durante toda a juventude e não se lhe resistiu em nada, ele conserva uma certa selvageria por toda a vida. (KANT, 1999, p. 14)
\end{abstract}

Assim ponderava Kant, ao definir o homem como único animal dependente da educação, exemplificando ainda que "[...] se, por exemplo, um animal, ao vir ao mundo, gritasse, como fazem os bebês, tornar-se-ia com certeza presa dos lobos e de outros animais selvagens atraídos pelos seus gritos" (KANT, 1999, p.11).

A emergência da educação na infância, para Kant, parece ser ainda mais pujante, mas em Rousseau o caráter frágil do homem quando ainda criança também é marcante, sendo o juízo também fruto do processo educativo (ROUSSEAU, 2004).

Nesse caso, a disciplina é entendida como objeto imprescindível da própria existência da infância e por consequência, do mundo adulto. Como destacam Gondim e Veras

13 Do original "Permítame repetir que no podemos esperar ningún mejoramiento real de la educación, que se extienda en una esfera amplia y se continúe progresivamente en el tiempo, aumentando su vigor, como corresponde, si no comenzamos por educar a las madres. Constituye su deber en el círculo doméstico, hacer lo que la instrucción escolar no puede lograr; prestar a cada niño individual aquel grado de atención que una escuela tiene que consagrar al conjunto; dejar que hable su corazón en los casos en que el corazón es el mejor juez; recabar por el afecto lo que la autoridad no hubiera conseguido" (PESTALOZZI, 1988, p. 12). 
(2017), em Kant "a inserção prévia da disciplina aproveita o caráter mais plástico da criança se comparado ao adulto para introjeção de certas posturas. Instituir disciplina em idade adulta aparece de forma mais dificultosa". Por isso, o período de tutela, para Kant, aparece como mais curto, em especial, se comparado aos preceitos de Rousseau, que leva a cabo o projeto de educação de Emilio até o seu casamento. O início do instinto sexual, por volta dos dezesseis anos, marcaria os limites da educação do preceptor em Kant, embora a formação profissional prosseguisse. A noção de menoridade, para este autor, também seria dissociável do estado cronológico do indivíduo criança, pois, para além do período natural de pequeno, ela estaria associada à

[...] submissão aos guias religiosos, intelectuais e mesmo a livros ao qual delegamos uma autoridade superior ao nosso julgamento. O esclarecimento em Kant é justamente o esforço de retirada dessa menoridade que não é natural: a "saída do homem de sua menoridade, do qual ele próprio é culpado". (GONDIM e VERAS, 2017, p. 109)

Nesse caso, diante da fase adulta, a razão e o juízo seriam de responsabilidade direta do indivíduo, cabendo-Ihes a busca da verdade e a maioridade pelo esclarecimento em um contexto de liberdade política. Por isso, a ideia de educação pública - em oposição à exclusividade da educação familiar, como em Rousseau - seria tão cara a Kant, pois em um contexto de carência econômica de grande parcela da população, se evitariam "hábitos, valores e preconceitos familiares danosos" (GONDIM e VERAS, 2017, p. 110). Em suma, se infância diz respeito a tempo, fase, estação, esta noção temporal também pode ser variável e por consequência, a intervenção em sua educação.

O conceito, nesse caso, mobiliza sentidos entre necessidade e autonomia, entre vazio intelectual e potencial cognitivo, tornando visível o aparato discursivo que é utilizado de acordo com as intenções ou interesses políticos e sociais dos discursos nos diferentes estratos do tempo.

\section{Considerações Finais}

É possível admitir que o conceito de infância em circulação no século XVII e início do XVIII tinha na criança uma "figura marginal em um mundo adulto" (HEYWOOD, 2004, p. 10). Estaria, portanto, relacionado a um maior número de aspectos negativos, como também já se lia nas obras de viés neoplatônico intituladas"A Cidade de Deus" e "Confissões", de autoria de Santo Agostinho (354430), redigidas no final do século IV, cujo foco recaía sobre a imperfeição e a natureza pecaminosa da imaturidade infantil.

Já em meados do século XVIII, especialmente a partir de Rousseau, percebe-se um movimento de valorização da infância como período com características próprias, de pureza a ser preservada, e relevante para a concretização do projeto do homem moderno. Nesse contexto, o respeito à natureza, a participação da família e o papel da educação pú- 
blica se tornariam elementos discursivos a serem mobilizados de acordo com as posições de seus enunciadores. Assim, o espaço de experiência da infância passaria a se relacionar intrinsecamente com o horizonte de expectativas a respeito do homem adulto em processo de constituição.

A análise do conceito de infância permite-nos infindáveis camadas interpretativas. A despeito das variações dos sentidos para o conceito, camadas mais profundas ainda podem ser identificadas, pois consideramos que falar de infância é, ao mesmo tempo, reunir os limites entre a incompetência ou impropriedade do estar criança e ainda admitir a noção de infância como período marcado por um estado próprio, portanto, capaz de revelar aspectos relevantes de sua experiência, como temas correntes nos discursos políticos e sociais.

Caberiam ainda, para análises futuras, reflexões sobre os desdobramentos desse conceito na modernidade que se seguiria, percebendo sua circulação semântica também nos séculos $\mathrm{XIX}$ e $\mathrm{XX}$, se considerarmos as profundas transformações que o processo de industrialização imprimiu ao mundo moderno, bem como impactos dos conflitos mundiais das duas Grandes Guerras no terreno da linguagem em relação às práticas sociais, a exemplo da educação da infância. Este é um período fértil para as questões aqui propostas, tendo em vista que a infância passa a ser considerada um período digno de atenção universal, a partir dos debates permeados por teorias centradas no desenvolvimento infantil, como as defendidas por Piaget, o que estimulou o interesse pelos direitos das crianças em esfera internacional, culminando na assinatura da Convenção sobre os Direitos da Criança (CDC), em 1989 (FAÇANHA, 2011).

Concluímos nesse exercício, enfim, que o estudo dos conceitos no âmbito da história da educação permite-nos perseguir e problematizar os discursos e ações dos homens no tempo por meio da análise do debate público, identificando tensões entre o contexto de enunciação que pode definir permanências e descontinuidades dos sentidos históricos de conceitos fundamentais para as ciências humanas e para a educação como o da infância. 


\section{Referências}

ARCE, Alessandra. A imagem da mulher nas ideias educacionais de Pestalozzi: O aprisionamento ao âmbito doméstico (privado) e à maternidade angelical. In: Reunião Anual da ANPEd, XXIV, 2001, Caxambu - MG.Resumos e textos: Disponível em: <http://24reuniao.anped.org.br/tp.htm\#gt2/>. Acesso em: 15 abr. 2019.

AMORIM, Litza de Oliveira. Cartas sobre educação infantil de Johann Heinrich Pestalozzi: imagens de mãe na correspondência de educadores, 2018. 127 p. Dissertação de Mestrado - Universidade Metodista de Piracicaba, Pós-Graduação em Educação, Piracicaba.

ARIĖS, Philippe. História social da criança e da família. Tradução de Dora Flaksman. Rio de Janeiro: LTC, 1975.

BASTOS, Maria Helena Camara. Apresentação. In: FROEBEL, Friedrich. A Educação do homem. Tradução de Maria Helena Câmara Bastos. Passo Fundo: UPF, 2001.

BERMAN, Marshall. Tudo que é sólido desmancha no ar: a aventura da modernidade. Tradução de Carlos Felipe Moisés; Ana Maria L. Ioriatti. São Paulo: Companhia das Letras, 2007.

BECCHI, Egle. Retórica de Infância. Revista Perspectiva, NUP/CED, Editora da UFSC, Florianópolis, n. 22, ago-dez, p. 63-95, 1994. Disponível em: https://periodicos.ufsc.br/index.php/perspectiva/ article/viewFile/10743/10258. Acesso em: 11 abr. 2019.

BOBBIO, Norberto; MATTEUCCI, Nicola; PASQUINO, Gianfranco. Dicionário de política. Tradução de Carmen C. Varriale, Gaetano Lo Mônaco, João Ferreira, Luís Guerreiro Pinto Cacais e Renzo Dini. Brasília: Editora da UNB, 1998.

BOYDEN, Jo. Childhood and the policy makers: a comparative perspective on the globalization of childhood. In: JAMES, Alisso.; PROUT, Alan. (Ed.). Constructing and reconstructing childhood: contemporary issues in the sociological study of childhood. London: Falmer, 1997. p. 190-229.

CASSIRER, Ernst. A filosofia do iluminismo. Tradução de Alvaro Cabral. Campinas, SP: Editora Unicamp, 1992.

CLARKE, John. Histories of Childhood. In: WYSE, Dominic (ed.). Childhood Studies: an introduction. Oxford: Blackwell Pub., 2004.

CHARTIER, Roger. Leituras e leitores na França do Antigo Regime. Tradução Álvaro Lorencine. São Paulo: Editora Unesp, 2004.

CHARLOT, Bernard. A mistificação pedagógica: realidades e processos ideológicos na teorida da educação. Tradução de Ruth Rissin Josef. Rio de Janeiro: Zahar Editores, 1979.

COSTA, Jean Carlo de Carvalho. Ideias, conceitos, contextos: a contribuição de Reinhart Koselleck à escrita da História da Educação. Revista Brasileira de História da Educação, Maringá-PR, v. 17, n. 4 (47), p. 54-80, Out./Dez. 2017.

DE MAUSE, Lloyd. Historia de la infancia. Madri: Alianza Universidad, 1991. 
DIDEROT, Denis. Oeuvres Complètes. Tome XII. Paris: J.L.J. Brière, 1891. Disponível em:

D'HAUCOURT, Geneviève. A vida na Idade Média. Tradução de Marisa Déa. São Paulo: Martins Fontes, 1994.

ELIAS, Norbert. O Processo Civilizador: uma história dos costumes. Tradução de Ruy Jungman Vol. 1. Rio de Janeiro: Zahar, 1994.

FAÇANHA, Luisa Café Figueiredo. A Construção Social das Crianças-Soldado: representações e dilemas dentro do marco regulatório da ordem internacional do Pós-Guerra Fria. Rio de Janeiro, 2011. 136p. Dissertação de Mestrado - Instituto de Relações Internacionais, Pontifícia Universidade Católica do Rio de Janeiro.

FERREIRA, Antônio Gomes. Modernidade, Higiene e controle médico da Infância e da escola. In: ALMEIDA, Malu (org.) Escola e Modernidade: saberes, instituições e práticas. Campinas: Alínea, 2004, p. 97-111.

FRABBONI, Franco. A escola infantil entre a cultura da infância e a ciência pedagógica e didática. In: ZABALZA, M. Qualidade em educação infantil. Porto Alegre: Artmed, 1998. cap. 4, p. 63-92.

FREITAS, Marcos Cezar de; KUHLMANN, Moysés. Apresentação. In: (orgs.). Os intelectuais na história da Infância. São Paulo: Cortez, 2002, p. 7-9.

FROEBEL, Friedrich. A Educação do homem. Tradução de Maria Helena Câmara Bastos. Passo Fundo: UPF, 2001.

GÉLIS, Jacques. A individualização da criança. In: ARIĖS, Philippe, CHARTIER, Roger (orgs.). História da vida privada. Tradução de Hildegard Feist. São Paulo: Companhia das Letras, 1991, v.3, p.311-29.

GONDIM, Hamilton Cezar Gomes; VERAS, Roberto Pereira. A pedagogia kantiana e a educação em Rousseau: comparações morais e políticas: Saberes (Natal), v. 1, p. 99-114, 2017.

HEYWOOD, Colin. Uma história da infância. Tradução de Roberto Cataldo Costa. Porto Alegre: Artmed, 2004.

HERRERO, María del Carmen G. Elementos para una historia de la infancia y de la juventud a finales de la Edad Media. Zaragoza: Universidad de Zaragoza, 1997.

. Del nascer y el vivir: fragmentos para una historia de la vida en La Baja Edad Media. Zaragoza: Intituicíon Fernando el Católico: 2005.

HOBSBAWN, Eric. A era das revoluções: Europa 1789-1848. Tradução de Maria Tereza Lopes Teixeira Lopes Teixeira e Marcos Penchel. Rio de Janeiro: Paz e Terra, 1991.

JASMIN, Marcelo G. História dos Conceitos e Teoria Política e Social: referências preliminares. Revista Brasileira de Ciências Sociais, v. 20, n. 57, 2005. Disponível em: <http://www.scielo.br/pdf/ rbcsoc/v20n57/a02v2057.pdf>. Acesso em: 10 mar. 2019.

. Apresentação. In: KOSELLECK, Reinhart. Futuro passado: contribuição à semântica dos tempos históricos. Tradução de Wilma Patrícia Maas e Carlos Almeida Pereira. Rio de Janeiro: Contraponto; Ed. PUC-Rio, 2006. 
História dos Conceitos e Teoria Política e Social: Referências Preliminares. Revista Brasileira de Ciências Sociais, v 20, n. 57, 2005.

KANT, Immanuel. Sobre a Pedagogia. Tradução de Francisco Cock. $2^{a}$ ed. Piracicaba: Editora Unimep, 1999.

KELLY, Donna Darling. Uncovering the History of Children's Drawing and Art. Westport, Connecticut, London: Praeger, 2004.

KOSELLECK, Reinhart. Futuro passado: contribuição à semântica dos tempos históricos. Tradução de Wilma Patrícia Maas, Carlos Almeida Pereira e César Benjamin. Rio de Janeiro: Contraponto, Editora PUC-Rio, 2006a.

. A response to comments on the Geschichtliche Grundbegriffe. In: Hartmut Lehmann e Melvin Richter (eds.), The meaning of historical terms and concepts: new studies on Begriffsgeschichte, Washington, D.C., German Historical Institute, 1996.

. Uma resposta aos comentários sobre o Geschichtliche Grundbegriffe. In: JASMIN, Marcel Gantus; FERES JÚNIOR, João (Orgs.). História dos conceitos: debates e perspectivas. Rio de Janeiro: PUC Rio, 2006b.

KRAMER, Sonia. Infância, cultura contemporânea e educação contra a barbárie. In: Bazílio, Luiz Cavalieri; Kramer, Sonia. Infância, educação e direitos humanos. São Paulo: Cortez, 2003. p. 83- 106.

KOHAN, Walter Omar. Infância e Educação em Platão. Educação e Pesquisa, São Paulo, v. 29, n. 1.

KUHLMANN JR., Moysés. A circulação das ideias sobre a educação das crianças: Brasil, início do século XX. In: KUHLMANN JR., Moysés.; FREITAS, Marcos Cezar de (orgs.). Os intelectuais na história da infância. São Paulo: Cortez, 2002.

LEVIN, Esteban. La infancia en Escena. Buenos Aires: Ediciones Nueva Vision, 2002.

LOCKE, John. Ensaio acerca do entendimento humano. Tradução de Anoar Aiex e Jacy Monteiro. São Paulo: Abril Cultural, 1978 . (Coleção Os Pensadores).

LUSTIG, Andréa Lemes; CARLOS, Rinalda Bezerra; MENDES, Rosana Penha; OLIVEIRA, Maria Izete de. Criança e infância: Contexto histórico social. In: IV Seminário de Grupos de Pesquisa sobre crianças e infâncias - Ética e diversidade na Pesquisa. Goiânia, 2014.

MONTAIGNE, Michel de. Ensaios. Tradução de Sérgio Milliet. São Paulo: Editora 34, 2016.

NARANDOSKI, Mariano. Infância e poder: a conformação da pedagogia moderna. 1993. [229]f. Tese (doutorado) - Universidade Estadual de Campinas, Faculdade de Educação, Campinas, SP. Disponível em: <http://www.repositorio.unicamp.br/handle/REPOSIP P/253038>. Acesso em: 12 abr. 2019.

PESTALOZZI, Johann Heintich. Cartas sobre educación Infantil. Madrid: Editorial Tecnos, 1988.

PIOZZI, Patrizia. Utopias revolucionárias e educação pública: rumos para uma nova "cidade ética". Educ. Soc. [online]. 2007, vol.28, n.100, pp.715-735. 
PIEDRAHITA, María Victoria. El descubrimiento de la infancia (I): historia de un sentimiento. Colombia Revista De Ciencias Humanas, Editorial Universidad Tecnológica de Pereira v. 8, fasc. N/A, p.101 - 111, 2001.

PLATON. Oeuvres complètes. Paris: Galimard, 1950. 2 v.

POLLOCK, Linda. Los niños olvidados. Relaciones entre padres e hijos de 1500 a 1900. México: FCE, 1990.

RICHÉ, Pierre; ALEXANDRE-BIDON, Danièle. L'Enfance au Moyen Age. Paris: Seuil/ Bibliothèque Nationale de France, 1994.

ROUSSEAU, Jean-Jacques. Oeuvres Complètes de J.J. Rousseau,4 vols. Paris: A. Houssiaux, 1852.

ROUSSEAU, Jean Jacques. Ensaios Pedagógicos. Tradução de Priscila Grigoletto Nacarat. Bragança Paulista: Editora Comenius, 2004.

SARAT, Magda. Reflexões sofre infância: Elias, Mozart e Memórias de Velhos. Anais do IX Simpósio Internacional Processo Civilizador: Tecnologia e Civilização. Dourados: Ed. UFGD, 2005.

SARMENTO, Manuel Jacinto; PINTO, Manuel. As crianças, contextos e identidades. Braga, Portugal. Universidade do Minho. Centro de Estudos da Criança. Ed. Bezerra, 1997.

SNYDERS, Georges. La pédagogie en France aux XVIle et XVIIle siècles. Paris, P.U.F., 1965, 459 p. Bibliogr. (Coll. Bibliothèque scientifique internationale. Section pédagogie).

SOUZA FILHO, Homero Santos. Educação e desnaturação de Emilio de Rousseau. 2015. $237 f$. Dissertação (Mestrado) - Faculdade de Filosofia, Letras e Ciências Humanas. Departamento de Filosofia. Universidade de São Paulo.

STEARNS, Peter. A infância. Tradução de Mirna Pinsky. São Paulo: Editora Contexto, 2006.

SNYDERS, Georges. La pédagogie en France aux XVIle et XVIIle siècles. Paris, P.U.F., 1965, 459 p. Bibliogr. (Coll. Bibliothèque scientifique internationale. Section pédagogie).

SZABOLCS, Enicö. La place de l'enfant dans la société e dans la famille chez Diderot. Acta Universitatis Szegediensis de Attila József Nominatae: Acta Romanica. Tom. 29, p. 127-138, 2015.

TORRANO, Corrad Vilanou; CASTILLO, Xavier. La historia conceptual en la historiografia de la educación: hacia una historia del pensamiento pedagógico. Encounters, n. 15, pp. 161-180, 2014.

TOURAINE, Alain. Crítica da modernidade. Tradução de Elia Ferreira Edel. Petrópolis, RJ: Vozes, 1994.

TRÖHLER, Daniel. Pestalozzi y la educacionalización del mundo. Barcelona: Octaedro, 2014.

VIEIRA, Carlos Eduardo. Intelligentsia e intelectuais: sentidos, conceitos e possibilidades para a história intelectual. Revista Brasileira de História da Educação, Campinas, v. 8, n. 1, jan./abr., 2008. Disponível em: http://www.rbhe.sbhe.org.br/index.php/rbhe/artic

le/view/109 Acesso em: 12 abr. 2019. 